\title{
II.1. \\ Constitución de la Sociedad Cooperativa en la nueva Ley General española 27/1999, del 16 de julio
}

\author{
Dr. D. Javier Divar Garteiz-Aurrecoa
}

\section{Mercantilidad}

La nueva Ley General determina que las Sociedades Cooperativas se constituyen como entes económicos («para la realización de actividades empresariales» y al objeto de desarrollar «cualquier actividad económica»: Art. $1 .{ }^{\circ}$, puntos 1 y 2.). La «mercantilidad cooperativa» se amplía porque no existe una posición normativa general respecto a la ausencia de ánimo de lucro de las cooperativas, como se prueba porque la Disposición Adicional Primera de la Ley General establece los requisitos singulares para que algunas Cooperativas puedan «ser calificadas como sociedades cooperativas sin ánimo de lucro». Luego, a sensu contrario, se entiende que en general lo tienen.

Si a ello añadimos las exigencias formales de escritura notarial y registro público jurídico (Art. 10, 1 y 2, respectivamente, de la Ley General de Cooperativas) en concordancia con el Código de Comercio (Art. 119), para la obtención ope legis de la personalidad jurídica (Art. 7 in fine de la L.G.C. y 116 párrafo $2 .^{\circ}$ del C. $^{\circ}$ de C. ${ }^{\circ}$, nos encontramos con que la nueva Ley General de Cooperativas de España acredita la mercantilidad de las Cooperativas por su objeto (Art. 1. ${ }^{\circ}$ ), por su causa lucrativista (concordante con el Art. 116 párrafo primero del $C{ }^{\circ}$ de $C .{ }^{\circ}$ ) y por las formalidades que implican el otorgamiento de la personalidad jurídica general mercantilista (Arts. $7^{\circ}$ y $10 .^{\circ}$ de la L.G.C.). Pero además, como es sabido, el propio Código de Comercio en su Art. 124, equiparando indebidamente a Mutuas y Cooperativas, las declara mercantiles «cuando se dedicaren a actos de comercio extraños a la mutualidad». 
Es cierto que en el siglo XIX las Cooperativas actuaron como sociedades cerradas (mutuales) para defenderse de un medio político hostil y de una competencia capitalista salvaje. Pero en la actualidad, la generalidad del cooperativismo está abierto a terceros, por lo que incluso en puridad normativa (aplicación literal del Art. 124 del C. ${ }^{\circ}$ de C. ${ }^{\circ}$ citado) son sociedades mercantiles.

Así, resulta superfluo (y exageradamente justificatorio de una legislación artificiosamente «extramercantil»), el Art. 4-1 de la nueva L.G.C. (y concordantemente con él los correspondientes de las legislaciones autonómicas), cuando dice que las Cooperativas podrán operar con no socios «sólo cuando lo prevean los Estatutos»... Lógicamente la determinación de la mercantilidad, a estos efectos, se deja a la libertad de cada Cooperativa (y en cualquier momento, por modificación de sus Estatutos).

$Y$ es que resulta difícil compaginar la mercantilidad de las Cooperativas actuales (en general) con la cesión exclusiva de la materia a las Comunidades Autónomas (tema meramente político pero no técnicojurídico ni económico), bordeando la propia distribución competencial de la Constitución.

\section{Ambito de aplicación de la Ley}

Aparte del caso singular de Ceuta y Melilla, el Art. $2 .^{\circ}$ de la nueva L.G.C. establece que se aplicará esta legislación «a las sociedades cooperativas que desarrollen su actividad cooperativizada en el territorio de varias Comunidades Autónomas, excepto cuando en una de ellas se desarrolle con carácter principal».

Este texto difícilmente casa con la doctrina del Tribunal Constitucional en el tema de las aplicaciones legales y los conflictos normativos en materia cooperativista, asentada principalmente en la Sentencia del 29 de julio de 1983, en relación al recurso de inconstitucionalidad de la ya derogada Ley Vasca de Cooperativas de 1982, que trató de asentar el criterio mercantil del domicilio para determinar la aplicación de Ley.

En efecto, el Tribunal Constitucional determinó entonces que «el ámbito de la competencia asumida ...es en definitiva el punto central que debemos examinar» (Fundamento jurídico 1. ${ }^{\circ}$ ) y que, en relación a las competencias sobre cooperativas, se circunscribe a "las relaciones de carácter cooperativo que tengan lugar exclusivamente en el ámbito territorial» de la Comunidad Autónoma correspondiente. 
(Fundamento $4 .^{\circ}$, párrafo $\left.4 .^{\circ}\right)$. E incluso, el mismo párrafo de la Sentencia del Tribunal Constitucional, hace el distingo entre la competencia cooperativa del Estatuto Vasco (en el ámbito mercantil) y la competencia civil en materia de Fundaciones y Asociaciones, en la que el Estatuto de Autonomía (Art. 10-13) se refiere a la competencia sobre entidades que desarrollen principalmente sus funciones en el País Vasco. Por ello la conclusión del Tribunal Constitucional es la siguiente (Fundamento 4. ${ }^{\circ}$ párrafo in fine): «En conclusión, la Comunidad Autónoma del País Vasco tiene competencia para regular por Ley las cooperativas que llevan a cabo su actividad societaria típica, en los términos ya expuestos, dentro del territorio de la Comunidad, aun cuando establezcan relaciones jurídicas o realicen actividades de carácter instrumental fuera del territorio de la misma». Y para el Tribunal Constitucional son «instrumentales» las «relaciones jurídicas externas con terceros, que no pueden encuadrarse dentro de las «funciones» típicas de las mismas y que tienen un valor instrumental y necesario para la consecución del fin social».

Para remachar la posición doctrinal, el Fundamento Jurídico $7 .^{\circ}$ de la Sentencia del Tribunal Constitucional que comentamos, dice textualmente: "En efecto, una vez delimitada la competencia territorial del País Vasco en materia de cooperativas en el sentido de que comprende a las que realicen la totalidad de su actividad propiamente cooperativa en el ámbito territorial de la Comunidad...»

A la luz de la Doctrina Constitucional, que es clarísima como vemos, la excepción a la aplicación de la Ley General de Cooperativas del Art. 2-A in fine de la nueva Ley del 16 de julio de 1999, puede ser tachada de inconstitucional, en cuanto que la excepción de la actividad principal está expresamente rechazada en materia de Cooperativas (al caso concreto del País Vasco, pero por extensión para todo caso).

\section{Registro Mercantil y Unidad de Mercado}

La nueva Ley General de Cooperativas ha perdido la oportunidad, abierta por el Tribunal Constitucional, de imponer la publicidad mercantilista a las cooperativas de operatividad en el mercado, puesto que en la actualidad las cooperativas de Derecho Autonómico (la práctica totalidad) no tienen otra obligación jurídico-publicitaria que la de inscribirse en el Registro de Cooperativas de su Autonomía (salvo en los supuestos contemplados por el Reglamento del Registro Mercantil), sin 
conexión entre sí ni publicitación en el ámbito general estatal. Y como quiera que son miles las sociedades cooperativas en funcionamiento en España, algunas de ellas con cifras de facturación anual importantísimas y con numerosas operaciones mercantiles en extensos ámbitos geográficos, se produce en consecuencia una quiebra de la seguridad mercantilista general y aun de la unidad de mercado, que puede afectar incluso al Mercado Unico Europeo cuando esas Cooperativas operan, como sucede en muchos casos, en el ámbito de la Unión Europea.

El Tribunal Constitucional, en su Sentencia del 29 de julio de 1983, y refiriéndose a la antigua Ley de Cooperativas de 1974 y a su Reglamento de 1978, considera perfectamente legítimo que la normativa estatal imponga la inscripción mercantilista a las cooperativas de cualquier ámbito interno: "debemos afirmar que en los casos que relaciona el mencionado artículo 47.2 (se refiere el Tribunal Constitucional al Reglamento de Cooperativas de 1978), en cuanto afecten a cooperativas incluidas en el ámbito de la competencia territorial de la Comunidad (se refiere el Tribunal a la Vasca, pero por extensión es aplicable a cualquier otra), deberá efectuarse la toma de razón en el Registro Mercantil».

En este momento ya sólo queda conseguir el objetivo (salvo la modificación de la Ley General de Cooperativas) de la unidad mercantilista, por la «segunda vía» que prevé el Tribunal Constitucional en el último párrafo de su Sentencia que estamos comentando, que textualmente dice: «Problema distinto, que no es el aquí planteado, es el de que si en algún supuesto, por aplicación de la legislación general de carácter mercantil, debiera calificarse de sociedad mercantil algún tipo de cooperativa. En este caso sería de aplicación la legislación mercantil, que es competencia exclusiva del Estado de acuerdo con el artículo 149. 1.6 de la Constitución...».

Pero como tal declaración legislativa de mercantilidad cooperativista, podría suponer un vuelco en la actual situación, y ello políticamente no sería correcto, cabría también conseguir la unidad publicitaria mercantilista de seguridad jurídico-económica, sin entrar en declaraciones legales afectantes a la naturaleza jurídica de las cooperativas (y por ende sin entrar en conflictos competenciales) mediante la promulgación de una modificación de la normativa del Registro Mercantil que declarara el registro mercantil obligatorio de las Sociedades Cooperativas. 